\title{
Psychiatric study of patients with severe burn injuries
}

\author{
ALFRED C WHITE
}

\begin{abstract}
About two-thirds of a consecutive series of patients severely injured with burns followed up one year after discharge were found to have psychological sequelae. Duration of hospital stay and the presence of certain mental illnesses were related to the incidence and severity of psychological symptoms. This relation did not apply to the site of the burn and the existence of a claim for compensation.
\end{abstract}

The incidence of post-traumatic neurosis in patients with burn injuries could be reduced by identifying and treating, soon after the accident, those who need psychiatric help.

\section{Introduction}

Interest in the psychological reactions of patients with burns was aroused by a fire in a nightclub in Boston, USA, when a high incidence of emotional disturbance was recorded soon after burning. ${ }^{1}$ About half the victims were found to have emotional problems 11 months later. ${ }^{2}$ More recently, in a study of 20 selected patients with burns six were found to have emotional problems secondary to their injury. ${ }^{3}$ After the bombing of several public houses in Birmingham a random sample of victims (not severely injured in the explosions) showed a high incidence of psychiatric sequelae two years after the event. ${ }^{4}$ Several other studies have indicated a high psychiatric morbidity after disasters; probably because of the sensational aspects of such disasters they have been more extensively studied than the effects of lesser accidents.

The nature and aetiology of post-traumatic emotional disorders remain controversial. It has been suggested that neurosis varies inversely with the seriousness of the accident and that "compensation neurosis" is a state of mind born out of fear, kept alive by avarice, stimulated by lawyers, and cured by verdict. ${ }^{5}$ This view was pursued by Miller, ${ }^{6}$ who analysed 200 patients with head injury referred for medicolegal assessment and also 50 patients who had received compensation (after all types of accident) in whom neurotic symptoms had been found on examination more than three years previously. Miller found an inverse relation between accident neurosis and the severity of the injury. Those who developed neurosis tended to be from the lower social classes and were more commonly employees of large organisations or nationalised industries rather than people working in a more intimate atmosphere. Neurosis was twice as common in men as in women. Miller's overwhelming conclusion was that accident neurosis was related to factors regarding compensation and the prospect of financial gain.

The aim of my investigation was to study the effect of a severe burn injury on a consecutive series of unselected adult patients and to determine the incidence and severity of post-traumatic psychological sequelae and identify those factors that might predict victims vulnerable to accident neurosis.

\footnotetext{
Department of Psychological Medicine, Queen Elizabeth Hospital and Medical Centre, Edgbaston, Birmingham B15 2TH
}

ALFRED C W'HITE, MD, MRCPSYCH, consultant psychiatrist

\section{Patients and methods}

The investigation was carried out on inpatients of the Birmingham Accident Hospital. A consecutive series of adult patients (aged 16 and over) with burn injuries admitted to the hospital between May 1975 and May 1976 were interviewed. A control group of accident victims who had not sustained burns matched for age and sex was also studied (only victims whose injuries were of sufficient severity to necessitate admission to hospital for seven days or more were included).

Those patients who lived within a defined area (the city of Birmingham and its close environs) were interviewed again one year after discharge from hospital. A clinical assessment of psychological change since the accident was made using a rating scale. In addition the patients were assessed using a structured questionnaire adapted from the general health questionnaire (D P Goldberg. MD thesis. University of Oxford, 1969). The adapted questionnaire was validated on three separate groups of people: a "normal" group, a group of accident victims not included in the general study, and a group of psychiatric day patients and inpatients. A high follow-up rate was considered to be essential, and thus follow-up interviews were by appointment and usually conducted in the victim's home.

\section{Results}

Altogether 142 consecutive patients with burn injuries and 136 accident victims who had not been burnt were interviewed within the week after their accident (unless the severity of their condition necessitated delay). The two groups were matched for sex and age but were largely similar in respect of other variables measured. In both groups the proportion of patients with certain mental and physical illnesses was higher than the proportion in normal populations. The groups also differed from normal populations in respect of their use of drugs and alcohol (ACW. Doctoral thesis. University of Birmingham, 1981). Of the 142 patients with burn injuries, 49 were women and 93 men; all of the women had sustained their injuries in non-industrial accidents, whereas only 34 of the men had done so. Of the 136 controls, 53 were women and $83 \mathrm{men}$; again all of the women had sustained their injuries in non-industrial accidents whereas only 54 of the men had done so.

Eighty-six patients with burns and 99 controls lived within the defined areas as described. Of these, 76 patients with burns and 87 controls were eventually traced and interviewed (follow-up rates of $88.4 \%$ and $87.9 \%$ respectively). Table I gives details of the 22 patients living within the area who were not interviewed; these patients differed from those who were followed up in the prevalence of problem drinking and other mental illnesses. Table II shows how the injuries were incurred in the two groups studied.

\section{PSYCHOLOGICAL SEQUELAE}

Psychological sequelae as measured by both the clinical rating and the adapted questionnaire were found in about two-thirds of the patients with burns. About one-third were thought to be moderately to severely psychologically affected one year after their accident. Table III compares the results obtained using the clinical rating and the questionnaire score:

\section{Examples of psychological sequelae}

Psychological sequelae took the form of anxiety or depressive states. Examples of these according to clinical severity are shown below.

Case 1 (Clinical rating 1 (questionnaire score 6); mild psychological sequelae; burns group)-A 20 -year-old man had been burnt by industrial cyanide when reinforced tubing on a pump burst. A year after discharge he was socialising less than before the accident, was generally more edgy and bad tempered, and felt more anxious (scared or panicky) than before. 
TABLE I-Details of the 22 patients who were "not available" for follow-up or could not be traced

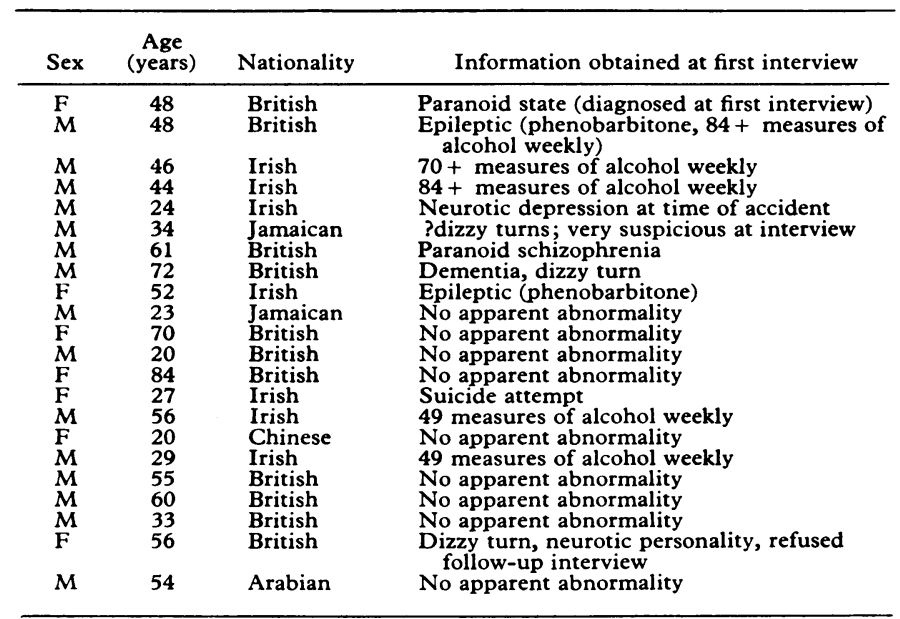

TABLE II-Types of burns and accidents in patients in study

\begin{tabular}{|c|c|c|c|c|}
\hline & \multicolumn{2}{|c|}{ Men } & \multicolumn{2}{|c|}{ Women } \\
\hline & $\underset{\text { Original }}{\text { group }}$ & $\begin{array}{l}\text { Follow-up } \\
\text { group }\end{array}$ & $\begin{array}{l}\text { Original } \\
\text { group }\end{array}$ & $\begin{array}{l}\text { Follow-up } \\
\text { group }\end{array}$ \\
\hline $\begin{array}{l}\text { Type of burn: } \\
\text { Molten metal } \\
\text { Hot liquid/fat } \\
\text { Chemical } \\
\text { Electrical } \\
\text { Hydrocarbon (petrol, etc) } \\
\text { Explosion } \\
\text { Cigarette } \\
\text { General conflagration } \\
\text { Domestic heater/fire } \\
\text { Uther/not classified } \\
\text { Type of accident (non-burn): } \\
\text { Road traffic accident } \\
\text { Fall (same level) } \\
\text { Fall (from height) } \\
\text { Hit (by object) } \\
\text { Hit (by person) } \\
\text { Machine injury } \\
\text { Cut } \\
\text { Other/unclassified }\end{array}$ & $\begin{array}{r}17 \\
18 \\
10 \\
4 \\
11 \\
15 \\
1 \\
5 \\
12\end{array}$ & $\begin{array}{r}8 \\
10 \\
7 \\
1 \\
4 \\
6 \\
1 \\
1 \\
2 \\
8 \\
17 \\
17 \\
8 \\
8 \\
3 \\
2 \\
9 \\
4 \\
4\end{array}$ & $\begin{array}{r}19 \\
1 \\
7 \\
2 \\
1 \\
4 \\
10 \\
5\end{array}$ & $\begin{array}{r}4 \\
20 \\
3 \\
3\end{array}$ \\
\hline
\end{tabular}

TABLE III-Comparison of clinical rating and questionnaire score in patients with burns*

\begin{tabular}{|c|c|c|c|c|}
\hline \multicolumn{3}{|c|}{ Clinical rating } & \multicolumn{2}{|c|}{ Questionnaire score } \\
\hline Rating & $\begin{array}{c}\text { No }(\%) \\
\text { of } \\
\text { patients }\end{array}$ & & Score & $\begin{array}{c}\text { No }\left(\begin{array}{c}\% \\
\text { of }\end{array}\right) \\
\text { of } \\
\text { patients }\end{array}$ \\
\hline $\begin{array}{l}\text { 1: No change } \\
2: \text { Mild change } \\
3: \text { Moderate change } \\
\text { 4: Marked change } \\
\text { 5: Severe change }\end{array}$ & $\left.\begin{array}{l}24(34 \cdot 8) \\
17(24 \cdot 6) \\
13(18 \cdot 8) \\
10(14 \cdot 5) \\
5(7 \cdot 2)\end{array}\right\} 28(40 \cdot 6)$ & $45(65 \cdot 2)$ & $\begin{array}{l}1-2 \\
3-7 \\
>8\end{array}$ & $\left.\begin{array}{l}28(40 \cdot 6) \\
16(23 \cdot 2) \\
25(36) \cdot 2\end{array}\right\} 41(59 \cdot 4)$ \\
\hline
\end{tabular}

*Seven patients were not classified using the clinical rating. The questionnaire score in all 76 patients was: $1-2,30$ patients $(39.5 \%) ; 3-7,19$ patients $(25 \%) ;>8$, 27 patients $(35 \cdot 5 \%)$.

Case 2 (Clinical rating 2 (questionnaire score 10); moderate psychological sequelae; burns group)-A 45-year-old woman employed as a children's attendant had fallen at home and been scalded by boiling water. One year after discharge her concentration was impaired, and on occasion she would not carry out ordinary everyday activities, was afraid to go out, and was depressed and irritable.

Case 3 (Clinical rating 3 (questionnaire score 16); considerable psychological sequelae; control group)-A 53-year-old woman had fallen down stairs and broken her right ankle. One year later at followup she cried during the interview and complained of lack of concentration, that she was missing much time off work, and that she had lost interest in outside activities, her social life, and her personal appearance. She said that she was edgy and bad tempered and felt depressed.

Case 4 (Clinical rating 4 (questionnaire score 22); severe psycho- logical sequelae; burns group)-A 37-year-old prostitute burnt in a house fire complained a year after discharge that she found it difficult 3 to concentrate, slept badly, did less work in the house (she no longer@ felt able to follow her "profession"), was not interested in everydayc activities, had not been going out socially, was very worried about her $\widehat{\Omega}$ appearance and thus would not undress in front of others (hence giving up work), felt afraid to go out, was bad tempered, anxious, and depressed, and had considered suicide.

Symptoms-The following selected symptoms (taken from the questionnaire) were elicited from patients with burns at follow-up 0 deterioration in concentration in $22(29 \%)$; reduced interest in everyday activities $(23 ; 30 \%)$; loss of interest in personal appearance $(12 ; 0$ $16 \%)$; less social activity $(29 ; 38 \%)$; worry about appearance $(29 ; 0$ $38 \%)$; sexual intercourse less or not satisfactory since accident $(14 \div$ $18 \%)$; fear of going out $(16 ; 21 \%)$; increased irritability $(22 ; 29 \%) ;$ experiencing fear or panic $(19 ; 25 \%)$; feelings of unhappiness or depression $(28 ; 37 \%)$; "Wishing I was dead and away from it all" (eight; $11 \%$ ).

\section{Relation to area of burn}

Contrary to expectation, the area of body burnt bore no relation to윽 the incidence or severity of psychological sequelae, except that fewet. men with leg burns reported severe psychological symptoms.

\section{Relation to compensation}

Only 13 victims had a claim for compensation outstanding atur follow-up. All these victims were men and had been injured in an industrial accident. This group had significantly higher scores than men who had been injured in an industrial accident but were not $\omega$ claiming compensation. The difference between the two groups was not significant when they were matched for severity of injury.

\section{Relation to sex, social class, and nature of accident}

No significant difference between the incidence of psychological sequelae in men and women was found. Similarly, victims of industria accidents did not have a higher incidence of psychological sequelaes than victims of non-industrial accidents. No significant relation was found between the social class of women with burn injuries and then proportion experiencing severe psychological sequelae. There was such a relation, however, among men with burn injuries: those from sociaf classes IV and V were more liable to have neurotic problems one yearo after their injury.

\section{Comparison of groups at follow-up}

There was a tendency for a higher proportion of patients with burns to suffer moderate to severe psychological sequelae, but this did not reach significance.

\section{PREDICTIVE FACTORS}

The following factors elicited at the interview immediately after the accident bore a relation to the incidence of psychological sequelae a $\frac{D}{2}$ measured with the questionnaire. (1) Patients aged 36-45 years $(p<0.01)$ and those living alone $(p<0.001)$ or with three or mores children $(p<0.05)$. (2) Certain psychological states (anxiety, depressive reaction, and personality disorder $(p<0.001))$; this relation was not upheld for other psychological illnesses-for example, psychosis. (3) Duration of admission $(p<0.01)$ and severity of injury $(p<0.02)$.

\section{Discussion}

Much emphasis has been given to the concept of compensation? neurosis. Victims of severe injury who later suffer psychologicaß symptoms are often regarded with suspicion in the belief tha their symptoms are motivated by the prospect of financial gain 8 In this study of patients with severe burn injury some two-thirds్ of the victims suffered psychological sequelae one year aftef their accident; one-third of the total were moderately or severelye 
affected. Only 13 out of 76 victims were claiming compensation, and only six were considered to be suffering from appreciable post-traumatic neurosis.

No consistent relation was found between the area of burn and emotional problems after the accident. The particularly unpleasant nature of a burn injury led me to postulate that posttraumatic neurosis would be significantly more common in accident victims who sustained burns than in victims of other injuries. This was not the case. Women and men were equally affected, though more sequelae were found in men from the lower social classes. Predictive factors for a poor outcome appear to include the severity of the injury and duration of stay in hospital (both obviously linked), the presence of certain mental conditions that are identifiable in the first few days after the accident, and the presence of certain other factors including age and family size.

Maguire et $\mathrm{al}^{7}$ showed that identification of those needing psychiatric help after mastectomy led directly to psychiatric intervention and consequent reduction in psychiatric morbidity. The incidence of post-traumatic neurosis could be similarly reduced by identifying and treating patients with burn injuries who need psychiatric help.

\section{References}

${ }^{1}$ Cobb S, Lindemann E. Management of Cocoanut Grove burns at Massachusetts General Hospital. Ann Surg 1943;117:814-24.

${ }^{2}$ Adler A. Neuropsychiatric complications in victims of Boston's Cocoanut Grove disaster. FAMA 1943;123:1098-101.

${ }^{3}$ Andreason NC. Suicide attempted by self-immolation. Am $\mathcal{f}$ Psychiatry $1975 ; 132: 5$.

4 Sims M, White A, Murphy T. Aftermath neurosis: psychiatric sequelae of Birmingham bombings in victims not seriously injured. Med Sci Law 1979;19:2.

${ }^{5}$ Kennedy F. Mind of injured worker: its effect on disability neurosis. Compensation Medicine 1946;1:19.

6 Miller H. Accident neurosis. Br Med f 1961 ; i:919-25.

${ }^{7}$ Maguire R, Tait A, Brooke M, Thomas C, Sellwood R. Effect of counselling on the psychiatric morbidity associated with mastectomy. $\mathrm{Br} \mathrm{Med} \mathcal{F}$ $1980 ; 281$ : 1454-6.

(Accepted 3 November 1981)

\title{
Healing of gastric ulcers after one, two, and three months of ranitidine
}

\author{
M G ASHTON， C D HOLDSWORTH，F P RYAN， M MOORE
}

\begin{abstract}
Ranitidine (150 mg twice daily) was compared with placebo in 42 patients with gastric ulcer. The study was conducted as a double-blind trial for one month, followed by an open assessment of one, two, and three months of ranitidine in the patients with persistent ulceration.

Thirty-eight patients completed the double-blind trial. Repeat endoscopy confirmed complete healing in 16 of the 21 who had received ranitidine and five of the 17 who had received placebo $(p<0 \cdot 01)$. The remaining 17 patients with persistent ulceration participated in the open assessment. The combined cumulative healing rates of ranitidine at four, eight, and 12 weeks were $73 \%, 88 \%$, and $97 \%$. There were no adverse effects or unusual reasons for withdrawal from the study (four patients).

Ranitidine appears to be a safe and highly effective treatment of gastric ulceration, with about $90 \%$ of ulcers healed after eight weeks.
\end{abstract}

\section{Introduction}

Ranitidine is a new histamine $\mathrm{H}_{2}$-receptor antagonist whose structure and action differ considerably from those of cimetidine. ${ }^{1}$ It is more potent on a molar basis, ${ }^{23}$ and a regimen of twice-daily dosage by mouth effectively inhibits secretion of

\footnotetext{
Gastroenterology Unit, Royal Hallamshire Hospital, Sheffield S10 2JF

M G ASHTON, MB, MRCP, senior registrar

C D HOLDSWORTH, MD, FRCP, consultant physician

$M$ MOORE, SRN, RFN, research nursing officer

Department of Gastroenterology, Northern General Hospital, Sheffield S5 7AU

F P RYAN, MB, MRCP, consultant physician
}

gastric acid. ${ }^{4}$ Such a regimen may also result in healing of duodenal ulcers. ${ }^{5-9}$ As ranitidine has not been evaluated in all types of peptic ulcer, we have undertaken a study of its efficacy in gastric ulceration. The study included a double-blind trial for one month, comparing ranitidine with placebo, and an open assessment of one, two, and three months of active treatment.

\section{Patients and methods}

We selected for the trial consecutive outpatients aged 18-75 attending for endoscopy and who were found to have active, non-malignant gastric ulceration. Criteria for exclusion were: past gastric or oesophageal surgery, ulcerogenic treatment, recent perforation, pyloric stenosis, pregnancy or possible conception during the trial, breast feeding, serious concurrent systemic illness, active upper gastrointestinal haemorrhage, raised serum transaminase activities, and cimetidine within the previous four weeks.

A double-blind assessment against placebo was chosen for the first stage of the trial $(a)$ because no studies had proved the efficacy of ranitidine in gastric ulceration, and we thought it important to establish this before embarking on comparative trials with any of the drugs currently accepted as effective; and $(b)$ because a comparative trial would have been more difficult to compare with previous trials on other agents, as a healing rate with placebo in our population would not have been available for comparison with these. We also wished to have a group of patients whose ulcers had healed spontaneously to serve as controls in a double-blind trial of maintenance treatment.

The nature of the study was explained to the patients and informed, written consent obtained. Before the trial patients underwent both clinical and laboratory assessment (haematological indices; blood urea, electrolyte, and creatinine concentrations; liver function tests; and urine analysis). The patients were then given a treatment pack and instructed in its use (stage 1). Each pack contained either ranitidine $150 \mathrm{mg}$ or identical placebo to be taken twice daily, together with a supply of antacid for symptomatic relief. Allocation to a particular regimen was double-blind according to a previously randomised schedule. Any withdrawal was recorded.

The patients were reviewed after two weeks, when the laboratory investigations were repeated together with clinical assessment. They were seen again after four weeks' treatment, when a repeat endoscopy 